\title{
A MEDIAÇÃO CAPITALISTA SOBRE O TRABALHO E AS IMPLICAÇÕES PARA A EDUCAÇÃO: APROXIMAÇÕES TEÓRICAS
}

\author{
Wesley da Silva Meira ${ }^{1}$, Paulo Fioravante Giareta ${ }^{2}$ \\ ${ }^{1}$ Mestrando em Educação pela Universidade Federal de Mato Grosso do Sul, Campus de Três Lagoas (PPGE- \\ CPTL/UFMS). ORCID iD: https://orcid.org/0000-0002-1042-4486. E-mail: wesleymeiraufms@gmail.com \\ ${ }^{2}$ Doutor em Educação pela Universidade Federal do Paraná (UFPR). Professor adjunto da Universidade Federal de \\ Mato Grosso do Sul (UFMS/CPTL) e do Programa de Pós-Graduação em Educação da Universidade Federal de Mato \\ Grosso do Sul, Campus de Três Lagoas (PPGE-CPTL/UFMS). ORCID iD: https://orcid.org/0000-0002-0649-4756. E-mail: \\ pfgiareta27@yahoo.com.br
}

\section{RESUMO}

O presente trabalho tem por objeto a análise da caracterização histórica da categoria trabalho no âmbito da sociedade capitalista e suas implicações sobre o sistema de ensino de países como o Brasil. Responde pelo objetivo de elucidar como o mundo do trabalho se organiza e se transmuta historicamente, bem como indicar modelos e proposta educativas que estas mudanças exigem da educação. Metodologicamente, estrutura-se a partir da revisão bibliográfica assentada sobre um exercício teórico dialético. $O$ trabalho possibilita perceber que as caracterizações e disciplinamentos exigidos pelo mundo capital ao trabalho implicam, consequentemente, em exigências reformistas para o âmbito da educação, possibilitando perceber a contínua aplicação de um aparato reformista em educação, justificado como necessário para a adequação formativa do indivíduo face às novas exigências do mundo do trabalho.

Palavras-Chave: Sociedade. Capital. Mundo do trabalho. Educação.

\section{THE CAPITALIST MEDIATION ON WORK AND THE IMPLICATIONS FOR EDUCATION: THEORETICAL APPROACHES}

\section{ABSTRACT}

The present work aims to analyze the historical characterization of the work category within the capitalist society and its implications on the education system of countries such as Brazil. It responds to the objective of elucidating how the world of work is organized and transmuted historically, as well as indicate educational models and proposals that these changes require of education. Methodologically, it is structured from the bibliographic review based on a dialectical theoretical exercise. The work allows us to perceive that the characterizations and disciplines required by the capital world to work imply, consequently, reformist requirements for the field of education, making it possible to perceive the continuous application of a reformist apparatus in education, necessary for the individual's formative adequacy in the face of the new demands of the world of work.

Keywords: Society. Capital. World of Work. Education.

\section{MEDIACION CAPITALISTA SOBRE EL TRABAJO Y LAS IMPLICACIONES PARA LA EDUCACION: ENFOQUES TEÓRICOS}

\section{RESUMEN}

El presente trabajo tiene como objetivo analizar la caracterización histórica de la categoría de trabajo dentro de la sociedad capitalista y sus implicaciones en el sistema educativo de países como Brasil. Responde al objetivo de esclarecer cómo se organiza y transmuta el mundo del trabajo históricamente, así como indicar los modelos educativos y las propuestas que estos cambios requieren de educación. Metodológicamente, se estructura a partir de la revisión bibliográfica basada en un ejercicio teórico dialéctico. El trabajo nos permite percibir que las caracterizaciones y disciplinas requeridas por el mundo 
capital para trabajar implican, en consecuencia, en las demandas reformistas para el alcance de la educación, lo que permite percibir la aplicación continua de un aparato reformista en la educación, justificado como necesario para la adecuación formativa del individuo frente a las nuevas demandas del mundo del trabajo.

Palabras clave: Sociedad. Capital. Mundo del Trabajo. Educación.

\section{INTRODUÇÃO}

A literatura vinculada à perspectiva crítica ajuda a construir categorias que viabilizam a análise histórico-dialética dos processos formativos dos mais diversos sistemas educacionais em curso na sociedade capitalista contemporânea. Isso posto, figura-se como central na presente análise a categoria trabalho, especialmente a sua caracterização histórica a reboque da mediação do capital.

A análise parte da tese de que a apropriação e disciplinamento do trabalho no contexto da sociedade capitalista implicam de modo consequente na apropriação e disciplinamento das políticas, propostas e práticas educativas. Assume, neste viés, a perspectiva de que as mudanças que ocorrem no sistema de produção mundial e o capital reestruturam as próprias formas de produzir que incidem potencialmente sobre o mundo do trabalho e, consequentemente, sobre o perfil de como a sociedade observa sua realidade cultural e educacional.

Assim, este texto responde pelo objetivo de elucidar como o mundo do trabalho se organiza e se transmuta historicamente e indicar modelos e proposta educativas que estas mudanças exigem da educação. Exercício que se estrutura a partir de dois movimentos principais: o Primeiro busca demonstrar a caracterização histórica do trabalho; e o segundo busca indicar a caracterização do trabalho mediada pelo capital e suas implicações para com os modelos de organização do ensino.

O presente artigo está vinculado a um conjunto de pesquisas em desenvolvimento no GForP - Grupo de Estudo e Pesquisa em Formação de Professores, no âmbito da UFMS Universidade Federal de Mato Grosso do Sul, com o objetivo de elucidar os fundamentos políticopedagógicos das reformas curriculares em curso no Brasil, especialmente, a reforma oficializada pela nova BNCC - Base Nacional Comum Curricular.

\section{DELINEAMENTO METODOLÓGICO}

Metodologicamente, o trabalho responde pela revisão bibliográfica assentada sobre um exercício teórico dialético, enquanto "exercício situado no plano da realidade, no plano da história, sob a forma da trama de relações contraditórias, conflitantes, de leis de construção, desenvolvimento e transformação dos fatos" (FRIGOTTO, 1997, p. 75), bem como possibilidade teórica e instrumento lógico de interpretação da realidade, sendo capaz de indicar um caminho epistemológico para o exercício da interpretação da proposta em análise. (BENITE, 2009).

O estudo pauta-se em um exercício de investigação dos processos históricos do trabalho que reverberam implicações nos modelos de educação na sociedade. Neste sentido, Kozul (2014), Bloch (2009) e Tocqueville (1997) oferecem-nos a interpretação contextual sobre as relações histórico-sociais do trabalho, desde a sua caracterização feudal até o advento industrial do sistema Capitalista assentada sobre a ideologia do estado burguês.

Frigotto (2011), Ribeiro (2011), Taylor (1966) e Antunes $(2009 ; 2018)$ contribuem tanto para a caracterização histórica do trabalho sob a égide capitalista de mediação e apropriação das condições de produção e acumulação pelos modelos fordista/taylorista, toyotista e neoliberal, quanto para a compreensão do conjunto de mutações em curso no mundo do trabalho e suas implicações ideológicas, políticas, econômicas e culturais.

Por fim, a mutações exigidas pela mediação capitalista sobre o trabalho demandam novas adequações e alinhamentos dos sistemas educativos, que autores como Francelino (2003); Gatti Junior (2010); Jacomeli (2010); Ramos (2001) e Silva (2016) os identificam na teoria do capital humano, na pedagogia tecnicista, na pedagogia da qualidade total e na própria pedagogia de competências e habilidades que em Brasil $(1998 ; 2018)$ passam a disciplinar a própria estrutura dos currículos educacionais do Brasil, impactando no trabalho dos professores e 
demarcando os indicadores e metas a serem alcançados pela educação do país.

\section{A CARACTERIZAÇÃO HISTÓRICA DO TRABALHO: APROXIMAÇÕES.}

O esforço inicial versa sobre a análise histórica da estruturação da sociedade pelo trabalho. Alguns estudos da antropologia social expõem que nas relações humanas há sempre um modelo de organização que prevalece em um povo, tal modelo reestrutura as condições de vida de cada indivíduo na cultura e sociedade em que estão inseridos. (KOZUL, 2014).

O modelo que prevaleceu anteriormente ao sistema capitalista foi o modelo feudal da Idade Média. Este sistema possuiu uma organização por castas similar à composição de classes do sistema do capital, mas apresentou diferenças no que tange aos deslocamentos do ponto de vista da riqueza, da produção material e comércio. No feudalismo, como bem descreve Bloch (2009), a riqueza privilegiava os donos de terras e o domínio político estava centrado nas mãos do rei e de seus senhores feudais. (BLOCH, 2009).

Por ser privilegiada a ocupação espacial, a economia desse sistema era baseada na agricultura e no frequente processo de trocas comerciais direcionadas à sobrevivência, mas não quer dizer, necessariamente, que não existia um sistema de compra e venda como no mercado do capital. Como explica Bloch (2009, p. 88) "a sociedade daquele tempo não desconhecia evidentemente nem a compra nem a venda, mas não vivia, como a nossa, da compra e da venda".

No modelo feudal a produção material era elaborada de maneira artesanal, de forma que o servo tomava para si o conhecimento da fabricação de todo o processo de produção. Assim, não era objetivado por eles que a produtividade seguisse em larga escala, pois nada ganhariam com sua força exacerbada de trabalho, bem como não era possível tecnologicamente à abstração dos materiais necessários que viabilizassem a produção em larga escala. O que lhes era objetivado parte de um acúmulo mínimo de bens para a sua subsistência. Logo, a troca, como modelo de comércio, era a forma mais adequada para a classe dos servis. (BLOCH, 2009).

O processo de transição do feudalismo ao capitalismo teve como epicentro a Europa Ocidental. Para o historiador argentino Pedro Kozul (2014) as transformações que ocorreram nesta transição tomaram uma enorme proporção, pois mudaram e definiram estruturalmente todos os pontos centrais e periféricos socioeconômicos, políticos, culturais e ideológicos dos países de nosso globo terrestre. (KOZUL, 2014).

Nesta transição, houve a aproximação dos diversos grupos socioculturais e, por essa aproximação, cristalizava-se o amadurecimento de novas relações sociais em uma sociedade ocidental programada durante o final da crise medieval e na Era Moderna. O progresso sociocultural e econômico começou, portanto, a abrir horizontes para a formação de um novo modelo de sociedade, um modelo de sistema absolutista que trouxe práticas econômicas pautadas no desenvolvimento do comércio. 0 que possibilitou em tempos posteriores o surgimento do modelo capitalista e o desenvolvimento dos ideais econômicos pautados na prosperidade do comércio e do trabalho. (KOZUL, 2014; BLOCH, 2009).

Essas consolidações de novos poderes interessados na prosperidade dos comércios começaram a ganhar forças dentro do panorama social e, consequentemente, proporcionaram o surgimento de uma nova classe: a burguesa. Com efeito, essa nova classe visou suprir as práticas antigas dos feudos e do sistema absolutista e impor outras formas de deslocamento social que buscavam uma especialização e regulação do mercado de trabalho. Assim, os direitos de propriedade da terra passaram a ser redefinidos e as novas práticas deslocadas norteavam mecanismos de um controle mais geral, isto é, na centralização e unificação do poder nas burguesias urbanas. (KOZUL, 2014).

Por esta acepção que surgiram as revoluções. Colocados ante uma ideia de liberdade, igualdade e fraternidade o povo servil francês, operários, se juntaram aos burgueses responsáveis pelos recursos monetários na busca de mudanças nos meios de trabalho, produção, formação política e organização social. De fato, ao iniciar-se a Revolução Francesa, essa luta conseguiu marcar de vez o abandono do Feudalismo e a alteração do sistema absolutista europeu. (TOCQUEVILLE, 1997; KOZUL, 2014).

Diferentemente do processo de trabalho do feudalismo, em que a riqueza está na posse de terras, a primazia da riqueza no sistema de trabalho da burguesia está no comércio, ou seja, em quem possui os meios de produção em massa. Além de que, a prevalência do domínio 
politico está nas intermediações do mercado. Já os setores populares estão sempre interpretados na história como agentes de luta e peças de uso para a força de trabalho. (KOZUL, 2014).

Tocqueville observa com razão que a Revolução Francesa foi ao mesmo tempo "mestre" e "flagelo", isto é, foi um processo dinâmico de classes operárias, mas que mascarou uma ideologia puramente burguesa. Segundo o pesquisador, à medida que a obra política da revolução foi consolidando-se, pôs a verdade em evidência de suas aparências com os trabalhadores. A verdade que se pôs a tona revelou que a luta era apenas para facilitar 0 exercício do poder para com os burgueses e não para formar uma só classe de cidadãos com os mesmos direitos. Focalizaram em apagar a tradição absolutista e renovar costumes e hábitos de composições pré-estabelecidas do capital para se adequar aos novos meios de produção e trabalho que estavam voltados à acumulação de bens e propriedades. (TOQUECVILLE, 1997).

Se antes a produção e o acúmulo eram voltados à subsistência do individuo e ele próprio poderia sozinho e artesanalmente construir seus objetos, com os princípios da revolução e o avanço industrial aquele estilo de vida tornou-se inviabilizável. A produção e o acúmulo se tornaram intermediados por quem possui e quem consome os objetos. $O$ trabalhador operário foi obrigado a cooperar com outros trabalhadores para sobreviver dentro desse novo sistema manufatureiro e de produção em série, isto é, o modelo burguês capitalista da forma de organização do trabalho. (ANTUNES, 2009).

Todo esse panorama histórico da organização do trabalho é descrito pelo pesquisador Antunes (2009) como um sistema de metabolismo social do capital. Uma analogia ao sistema orgânico do metabolismo da vida. Para ele, o capital se estrutura em um sistema de mediações que o permite metabolizar e se transformar a cada crise e, assim, o trabalho passa a ser submetido ao capital. (ANTUNES, 2009).

O sistema de metabolismo social do capital nasceu como resultado da divisão social que operou a subordinação estrutural do trabalho ao capital. Não sendo consequência de nenhuma determinação ontológica inalterável, esse sistema de metabolismo social é, segundo Mészáros, o resultado de um processo historicamente

constituído, em que prevalece a divisão social hierárquica que subsome o trabalho ao capital. Os seres sociais tornaram-se mediados entre si e combinados dentro de uma totalidade social estruturada, mediante um sistema de produção e intercâmbio estabelecido. (ANTUNES, 2009. p. 21).

Neste sentido, o sistema capitalista de trabalho possui uma dinâmica viva capaz de exercer influência globalmente na organização social dos países como uma teia de interligações entre todo mercado exterior e é capaz de se renovar na medida em que suas crises o afeta, como se possuísse certo metabolismo próprio. Isso, pois, houve um deslocamento da relação harmônica entre o capital e o trabalho a partir da subordinação do sistema de mediações presentes no constructo social de sobrevivência pelo trabalho. (ANTUNES, 2009).

Antunes (2009) explica que no mecanismo do sistema de trabalho temos as mediações de primeira ordem cuja finalidade é a preservação das funções vitais da reprodução individual e societal e as mediações de segunda ordem que introduz elementos fetichizadores e alienantes de controle social. O capital, desta forma, se apropria da condição de trabalho harmônica das relações de primeira ordem em que o capital e o trabalho estão em níveis semelhantes e posteriormente desloca-se para as relações de segunda ordem, passando, desta forma, a ter uma certa hierarquia onde o capital possui uma posição superior e abaixo dele está o trabalho. (ANTUNES, 2009).

Para entendermos as mediações de primeira ordem pensemos no Feudalismo. As mediações e os comportamentos da maior parte dos indivíduos da Idade Média foram voltados à sobrevivência. A produção foi determinada diretamente para os níveis de consumo próprio juntamente com a atividade de trabalho não por remuneração monetária, mas sim por terras férteis ao plantio e proteção que garantia aquela forma de sobrevivência. Exatamente, em termos gerais, a finalidade desse tipo de mediação é a 
preservação das funções vitais da reprodução individual e societal. (ANTUNES, 2009).

Já na consolidação do Capitalismo na evolução histórica do sistema feudal e burguês, não há mais essa relação harmônica entre trabalho e capital de sobrevivência vital, mas sim elementos alienantes de controle. $O$ trabalho alimenta o sistema do capital e passa a ter uma relação mais vertical. Portanto, quem determina como vai ser a relação de trabalho é o próprio capital.

\section{A CARACTERIZAÇÃO DO TRABALHO PELA MEDIAÇÃO DO CAPITAL}

Com o advento da industrialização, a acumulação figura como uma das principais dinâmicas desse novo sistema produtor de mercadorias. Como reflete Ribeiro (2015) essa acumulação do capital não consiste em si em um acúmulo puramente de riquezas de consumo necessário e pessoal dos objetos e sim tem por finalidade o lucro. Assim, a exploração da força de trabalho se tornou foco do modelo de trabalho capitalista de produção, tomando como impulso motriz modos de controle sobre aquela força de trabalho para tornar-se possível seu constante crescimento. (RIBEIRO, 2015).

Em 1914 Henry Ford foi precursor de um sistema de produção que viabilizou o metabolismo do capital, tal sistema foi denominado de Fordismo. O Fordismo trouxe consigo uma grande novidade técnica de organização do trabalho: a esteira rolante. Com a introdução da esteira rolante, o trabalho se tornou mais acelerado e alcançou proporções enormes de produtividade devido ao fato que o trabalhador só precisaria ficar em uma posição fixa e o trabalho chegava até ele. (RIBEIRO, 2015).

Mas, somente a racionalização da organização do trabalho com o controle do ritmo, automatização e mecanização dos processos funcionais não foi suficiente para que o modelo capitalista de produção se expandisse incondicionalmente, ou seja, mesmo com a adesão racional do trabalho foram ainda geradas barreiras a serem superadas pelo Fordismo. Tais barreiras foram a titulo de exemplo à qualificação profissional da mão de obra e resistência dos trabalhadores ao ambiente e aos meios de produção. (RIBEIRO, 2015).

A proposta fordista se vincula no ideário de gerenciamento e racionalização científica do trabalho capitalista que tanto acenam para a superação de tais barreiras, quanto acomodam os interesses pela obtenção do melhor rendimento do trabalhador e do maior lucro possível. Proposta historicamente denominada de Taylorismo. O modelo Taylorista de regulamentação do trabalho foi desenvolvido por Frederick Winslow Taylor que propôs a substituição dos métodos empíricos por métodos científicos de trabalho e a divisão entre a gerência e os trabalhadores. Taylor (1966, p. 26) diz:

Ora, entre os vários métodos e instrumentos utilizados em cada operação, há sempre método mais rápido $\mathrm{e}$ instrumento melhor que os demais. Estes métodos e instrumentos melhores podem ser encontrados bem como aperfeiçoados na análise científica de todos aqueles em uso, juntamente com acurado e minucioso estudo do tempo. Isto acarreta gradual substituição dos métodos empíricos pelos científicos, em todas as artes mecânicas.

Nas relações de trabalho, as divisões entre execução e concepção técnica se tornaram fundamentais. Os ideais taylorista buscavam padrões da melhor qualidade possível entre tempo e movimento para garantir a eficiência do modelo de produção em massa. A busca desse padrão era essencialmente papel voltado a gerência que deveria administrar o comportamento, instrumentos e meios que aperfeiçoasse a execução das funções exercidas pelos trabalhadores. (RIBEIRO, 2015).

As buscas pelos melhores níveis de produtividade e qualificação não parou nas pesquisas realizadas por Taylor. Diante uma crise estrutural do Fordismo/Taylorismo ocorrida em meados da década de 70 foi preciso uma nova forma de organização do sistema de produção capitalista, isto é, uma nova metabolização do sistema do capital. Forma essa encontrada no Toyotismo japonês.

Tal crise ocorreu devido ao fato do modelo Fordista/Taylorista ter alcançado o seu núcleo central que é a acumulação do capital. De acordo com Antunes (2009), o surgimento da 
crise estava nítido e foi evidenciada por um quadro crítico onde os principais traços foram: a queda da taxa de lucro, o esgotamento do padrão de acumulação taylorista/fordista de produção, a hipertrofia da esfera financeira, a maior concentração de capitais, a crise do Estado do bem-estar social e o incremento acentuado das privatizações. (ANTUNES, 2009). Antunes (2009, p. 33) ainda aponta que:

Como resposta à sua
própria crise, iniciou-se
um processo de
reorganização do capital e
de seu sistema ideológico
e político de dominação,
cujos contornos mais
evidentes foram o advento
do neoliberalismo, com a
privatização do Estado, a
desregulamentação dos
direitos do trabalho e a
desmontagem do setor
produtivo estatal, da qual
a era Thatcher-Reagan foi
expressão mais forte; a
isso se seguiu também um
intenso processo de
reestruturação da
produção e do trabalho,
com vistas a dotar o
capital do instrumental
necessário para tentar
repor os patamares de
expansão anteriores.
(ANTUNES, 2009, p. 33 ).

Como apontado, esse processo de reorganização do capital e do sistema de produção capitalista do trabalho foi encontrado no Toyotismo japonês com o processo chamado de "flexibilização" que também seria apropriado no ocidente com o advento do Neoliberalismo. Historicamente, o Japão passou por outros fatores socioculturais que permitiram 0 surgimento do padrão de produção toyotista que se diferenciava dos modelos fordista/taylorista ocidentais.

O Toyotismo estruturou o sistema de organização e gestão do trabalho pelo processo denominado de "Just-in-time" que visava produzir no tempo certo e na quantidade correta os objetos. Havia, também, a prioridade do trabalho em equipe e o deslocamento do trabalhador ao exercício de múltiplas funções, da qual foi seguida pela concepção de qualidade total. Em termos gerais, essa concepção é o envolvimento dos trabalhadores para a melhoria da produção. (RIBEIRO, 2015).

Outro ponto marcante deu-se pela inexistência de um contrato formal de trabalho e a hierarquização entre as empresas ou a chamada terceirização, isto é, a busca de contratar pequenas empresas, subordiná-las e direcioná-las a ocuparem variados serviços, reduzindo, assim, a estrutura operacional das grandes empresas. O que diminui os custos de produção, economiza recursos e desburocratiza a administração. Além desses fatores, incluiu-se a política de gestão do trabalho integrada ao sistema de representação sindical. (RIBEIRO, 2015).

Vemos que o Toyotismo incluiu cada vez mais elementos alienantes ao sistema de trabalho. Todos esses elementos são, então, absorvidos pelas indústrias ocidentais e unidas as características do padrão de produção fordista/taylorista. Assim, essa nova gestão mais flexível e incerta transformou e configurou no ocidente a ideologia neoliberal. Essa desregulação neoliberal provocou fortes mudanças no modelo do capital ocidental. (RIBEIRO, 2015).

Observa-se em Os sentidos do trabalho e em $O$ privilégio da servidão a explicação de Antunes (2009) para essas mudanças. O autor explica que as mutações do parque produtivo neoliberal fortificaram a flexibilização total, a precarização total e o nascimento do processo chamado de uberização. A flexibilização total se resume a uma reestruturação produtiva do modelo do trabalho cuja hegemonia financeira e a competitividade são traços marcantes. (ANTUNES, 2009; 2018).

A precarização total se dispõe da ausência de regulamentação da força de trabalho e precarização dos trabalhadores no que concerne aos seus direitos sociais. O processo intitulado de uberização é, assim, uma resposta ao conjunto de mudanças que foram ocorrendo no modelo de flexibilização e precarização do trabalho, a qual é vista pela busca do trabalhador por novas alternativas de trabalho informalizadas e desregulamentadas devido ao desemprego. Por consequência, no modelo neoliberal o desemprego é inerente ao capital. (ANTUNES, 2009; 2018). 


\section{A MEDIAÇÃO CAPITAL DO TRABALHO E A EDUCAÇÃO: ALGUMAS APROXIMAÇÕES}

A partir da perspectiva das mediações de segunda ordem, explicadas por Antunes (2009), da apropriação de elementos alienantes, o trabalhador passa a responder a certa configuração de como o capital se organiza e determina as relações produtivas. O modelo fordista, enquanto primeira forma de caracterização destas mediações do capital sobre as relações produtivas e critérios de acumulação, responde pela organização de sistema de apropriação das condições de trabalho, que em última instância, determina a própria forma como as pessoas trabalham. (ANTUNES, 2009).

O Fordismo, conhecido como modelo de produção em escala - linhas de produção ou linhas de montagem - articulado para a produção e consumo em massa a qual visa de forma técnica e organizada a produtividade exacerbada. Esse processo de trabalho desencadeou um ritmo de forças produtivas que acelerou o crescimento do sistema capitalista e transformou interiormente $o$ modelo de vida social. (ANTUNES, 2009).

O maior poder de incidência histórica do modelo fordista como modelo de estruturação produtiva capitalista repousa na sua capacidade de se apropriar da racionalização científica proposta pelo Taylorismo. O taylorismo figura como a expressão racional de uso dos meios de produção ampliando os experimentos científicos nas relações de trabalho, objetivando, em termos práticos, maior produtividade com o mesmo número de pessoas e no mesmo tempo de trabalho. (ANTUNES, 2009).

Esse processo produtivo caracterizou-se, portanto, pela mescla da produção em série fordista com o cronometro taylorista, além da vigência de uma separação nítida entre elaboração e execução. Para o capital, tratava-se de apropriar-se do savoirfaire do trabalho, "suprimindo" a dimensão intelectual do trabalho operário, que era transferida para a esfera da gerência científica. A atividade de trabalho reduzia-se a uma ação mecânica e repetitiva. (ANTUNES, 2009, p. 39).
Esta caracterização não se restringiu às relações de produção. Buscou, também, viabilidade ideológica e cultural com profundo impacto sobre os modelos formativos necessários para sua afirmação e reprodução histórica. Proposição que foi assentada sob um modelo de formação técnica.

As pessoas que estavam em uma relação manual/manufatureira de produção precisaram renovar seus conhecimentos para um processo técnico do trabalho em virtude dessa nova organização e transmutação do sistema do capital, que era mais racionalizado. Para isso, o modelo de educação voltou-se para um modelo utilitário, pragmático e fragmentado chamado de pedagogia tecnicista. (SILVA, 2016).

A incidência do modelo de racionalização do sistema de produção capitalista expresso no Taylorismo/Fordismo, também recebe contornos nas teorias educacionais. A Teoria do Capital Humano, organizada a partir dos estudos de Schultz, no contexto da década de 1960, ao encerrar a compreensão do trabalho como capacidade de realizar tarefas manuais com baixa exigência de conhecimento e especialização, preconiza uma ideia de investimento em capital humano como investimento em escolaridade, treinamento e saúde.

No Campo da Educação, a teoria de capital humano gerou a concepção tecnicista sobre o ensino e sobre a organização da educação. $\mathrm{Na}$ concepção tecnicista, propagou-se a ideia de que a educação é o pressuposto do desenvolvimento econômico, chancelando a noção de que os investimentos em educação devem ser determinados pelos critérios do investimento capitalista. (SILVA, 2016, p. 203).

A proposta da pedagogia tecnicista chega ao Brasil a reboque do projeto do desenvolvimentismo econômico no âmbito da política do estado militarizado e de seu ideário de modernização nacional aos moldes do desenvolvimento capitalista industrial. Proposição que orienta as políticas educacionais a partir da proposta da Teoria do Capital Humano 
e da leitura restritiva da educação como formação de recursos humanos para o desenvolvimento a partir dos parâmetros da ordem capital. (SILVA, 2016).

Gatti Junior (2010) fala a respeito do apego da proposta tecnicista em desenvolvimento no Brasil. Esse apego deu-se à luz da teoria estrutural-funcionalista que teve na sua expressão política a teoria da modernização e, na sua face econômico-educacional, a teoria do capital humano, a qual viabilizou os processos de reformas adaptadoras da educação como instrumento de aperfeiçoamento da organização econômica e social.

As referidas reformas se materializam na Reforma Universitária da Lei 5.540 de 1968 que promove uma maior vinculação da educação superior às demandas de mercado e ao projeto político de modernização alinhado aos ordenamentos produtivos do capitalismo internacional e na Reforma do Ensino Primário e Secundário da Lei 5.692 de 1971. Tal lei acabou impondo a obrigatoriedade do ensino profissional para todos os jovens brasileiros e "a introdução de um currículo por áreas de estudo (não reconhecendo as disciplinas científicas) e com ênfase no desenvolvimento de habilidades, atitudes e conhecimentos necessários à integração no processo produtivo" (SILVA, 2016, p. 204).

Contudo, os modelos Fordista/Taylorista de produção e tecnicista na educação, a partir da década de 1980, apresentaram sinais de esgotamento tanto em sua capacidade de acumulação, quanto da reprodução das condições técnicas e culturais de sustentação deste ordenamento capital de acumulação. Requisitou, portanto, uma nova mutação do sistema do capital que se modificou em suas bases concretas e emergiu uma nova reestruturação produtiva: o modelo flexível do Toyotismo. (SILVA, 2016).

A mudança, aqui, não indica uma superação do modelo de apropriação do trabalho pelo capital, mas uma reestruturação das relações de trabalho conferindo maior ênfase ao aparelhamento tecnológico e apego aos métodos de gestão. $O$ apego ao gerencialismo, ferramentas da gestão empresarial no trabalho e na educação, deu sustentação à racionalização dos processos de trabalho alimentando o ideário de qualidade total e a inclusão massiva de tecnologia viabilizou a produção a partir de matrizes mais flexíveis.
Esta reestruturação reacionária das mediações capitalista de trabalho produziu igual impacto/acomodação no campo educacional. Conferiu-se profundidade aos pressupostos da Teoria do Capital Humano e nova roupagem à Pedagogia Tecnicista, agora traduzida por conceitos como Teoria das Competências, Sociedade do Conhecimento, Empregabilidade/Empreendedorismo, Qualidade Total, entre outros.

Estes deslocamentos teóricos se acomodam no próprio princípio da flexibilização e da precarização das relações de trabalho precipitadas pelo modelo Toyotista. Modelo de mediação capital do trabalho que se aporta na propaganda de que o indivíduo e o sistema de ensino são os únicos responsáveis pela relação emprego-desemprego. Esta proposta desloca o perfil, as competências e os conhecimentos do indivíduo para o posto/vaga de trabalho demandando do candidato e do sistema de ensino o esforço pedagógico para a adaptação do indivíduo ao emprego, pautado por níveis de competitividade regulada por proposta gerencial e por mecanismos de qualidade espelhados pelo ideário de qualidade total. (SILVA, 2016).

A incidência desta proposta para a educação ganha tanta consistência que até institutos como o IPEA - Instituto de Pesquisa Econômica Aplicada, fundação vinculada ao Ministério da Economia, Fazenda e Planejamento, em 1991, lançou um documento intitulado Gestão da Qualidade Total nas Escolas: um novo modelo gerencial para a educação, propondo-se a trazer elementos para a mediação das reformas educacionais em curso a partir da década de 1990.

O documento é explicito em indicar o modelo de qualidade objetivada pelo mercado como referência para a qualidade da educação. Parte da afirmativa que qualquer proposta com poder efetivo de qualificar a educação tem que se aportar no esforço de modernizar a gestão da educação, apresentando como ferramenta a proposta da Gestão da Qualidade Total como método moderno. $O$ documento define, então, a qualidade como aptidão de um produto ou serviço para satisfazer as necessidades daqueles que o utilizam considerando a harmonia entre os clientes, o produto e seu custo. Proposta que demanda forte envolvimento gerencial enquanto prática de controle atrelada a indicadores racionais capazes de demonstrar o envolvimento do sistema de ensino e dos clientes internos 
(alunos) e externos (familiares) no alcance das metas referendadas pelo mercado, a qual são traduzidas pelas categorias competências, conhecimentos e atitudes.

As referidas propostas acabam por fomentar o modelo das reformas educacionais na década de 1990 no Brasil com forte aceno para as políticas de controle a partir da implementação de políticas de avaliação centralizadas, externas à escola, em larga escala. Proposta que se estrutura a partir do ideário do controle e fiscalização gerencial como princípio de modernização e qualidade educacional.

Este ideário afetou, inclusive, a reforma curricular, que na década de 1990, apresenta a política dos Parâmetros Curriculares Nacionais (PCN) como condição para adequação da educação nacional ao mundo do trabalho. Veja:

$$
\begin{aligned}
& \text { Vivemos numa era } \\
& \text { marcada pela competição } \\
& \text { e pela excelência, em que } \\
& \text { progressos científicos e } \\
& \text { avanços tecnológicos } \\
& \text { definem exigências novas } \\
& \text { para os jovens que } \\
& \text { ingressarão no mundo do } \\
& \text { trabalho. Tal demanda } \\
& \text { impõe uma revisão dos } \\
& \text { currículos, que orientam o } \\
& \text { trabalho cotidianamente } \\
& \text { realizado pelos } \\
& \text { professores e especialistas } \\
& \text { em educação do nosso } \\
& \text { país. (BRASIL, 1998, p. 5). }
\end{aligned}
$$

A aderência do modelo Toyotista na mediação capitalista de produção tendo em vista a reorganização das bases de acumulação no contexto de crise estrutural do capital, se percebeu limitada, especialmente para o contexto ocidental, pois teve como consequência imediata o aprofundamento dos dispositivos da flexibilização e precarização. Neste sentido, no Ocidente houve a necessidade de um reordenamento, tal reordenamento recebe contornos teórico e prático no que passamos a denominar de neoliberalismo.

O neoliberalismo ganha contornos oficiais em 1989, no âmbito do Consenso de Washington, enquanto o receituário para ajustes econômicos acabou permitindo o livre movimento do capital e das mercadorias à custa da submissão dos estados nacionais, isto é, de seus trabalhadores e o conjunto de suas políticas, inclusive, as educacionais. Ou seja, o próprio estado está a serviço do grande arranjo capitalista de produção e acumulação.

O Estado que se orienta pela proposta neoliberal assume como pauta central de governança a promoção de uma ampla agenda de flexibilização de sua legislação sobre os recursos naturais, sociais, trabalhistas e educacionais, oficializando uma ampla política de precarização das relações de produção e maior gerencialismo sobre a políticas educacionais.

O neoliberalismo exige, assim, um duplo movimento da escola e dos sistemas de ensino. De um lado pauta o aprofundamento da lógica da flexibilização assentada sobre matrizes tecnológicas para dar conta da nova organização estrutural do mundo do trabalho e de outro lado o aprofundamento lógico do controle gerencial em nome da aproximação adaptativa da educação às lógicas ilimitadas de precarização das relações de empregabilidade.

Esta proposta resulta no aprofundamento das teses da Teoria do Capital Humano rejuvenescendo o tecnicismo pedagógico pela adoção da Pedagogia das Competências como fundantes das políticas de oferta e de avaliação dos projetos e sistemas de educação. No contexto das reformas educacionais no Brasil figura ilustrativo deste ideário o esforço reformista que resultou na implementação da nova Base Nacional Comum Curricular (BNCC), que se apresenta como uma proposta capaz de promover uma revolução epistemológica na educação conferindo centralidade às competências pré-definidas, objetivos de aprendizagem e produção de atitudes controladas. Observe que:

Na BNCC, competência é definida como a mobilização de conhecimentos (conceitos e procedimentos), habilidades (práticas, cognitivas e socioemocionais), atitudes e valores para resolver demandas complexas da vida cotidiana, do pleno exercício da cidadania e do mundo do trabalho. (BRASIL, 2018, p. 8).

O documento se apresenta em caráter normativo, isto é, que estabelece normas ou padrões, aqui, centrados em um conjunto orgânico e progressivo de aprendizagens 
essenciais que todos os alunos devem desenvolver ao longo das etapas e modalidades da Educação Básica (BRASIL, 2018). O que seria aprendizagens essenciais? Segundo o documento é o desenvolvimento de dez competências gerais, que consubstanciam, no âmbito pedagógico, os direitos de aprendizagem e desenvolvimento. (BRASIL, 2018). Contudo, a pedagogia das competências não aponta para uma mudança epistemológica da educação, mas para sua acomodação a partir de bases comportamentais. O termo competência parece estar ligado diretamente às políticas de gestão e ao cenário que envolve as relações de trabalho e formação.

A pedagogia centrada em competências pré-definidas parece atender adequadamente à necessidade de responsabilizar os indivíduos pelo esforço da empregabilidade no contexto de redução dos postos e condições de trabalhos, bem como no contexto da precarização das relações de produção como estratégia de redefinição da acumulação capital. Nas palavras de Frigotto (2015) implica no velho transvestido como novidade.

Ramos (2001, p. 38), nos ajuda a identificar neste deslocamento uma proposta de educação instrumentalizada para a racionalização dos novos arranjos da vida econômica e da produção, caracterizados pelas exigências de "flexibilização da produção e reestruturação das ocupações; integração de setores da produção; multifuncionalidade e polivalência dos trabalhadores; valorização dos saberes dos trabalhadores não ligados ao trabalho prescrito ou ao conhecimento formalizado".

Para Ramos (2001, p. 39) o deslocamento caracteriza o esvaziamento da qualificação como relação social, agora, transmutada no conceito de competência, que "originário das ciências cognitivas, surge com uma marca fortemente psicológica para interrogar e ordenar práticas sociais". Esse deslocamento é organizado, no âmbito educacional, a partir de propósitos como: reordenar conceitualmente a compreensão da relação trabalho-educação; institucionalizar novas formas de formar o trabalhador; e forma padrão de identificação do trabalhador para determinada ocupação.

Essa racionalidade (neo)tecnicista quando afirmada a partir de competências pré-definidas aprofunda a funcionalidade positivista do controle e da avaliação sobre a educação do trabalhador.

\section{CONCLUSÕES}

0 trabalho possibilita perceber que às caracterizações e disciplinamentos exigidos pelo mundo capital ao trabalho implica, consequentemente, em exigências reformistas para o âmbito da educação. Demonstrando, portanto, que são as mutações no sistema do capital que modificam o processo educativo e não o contrário.

A referida constatação possibilita compreender a passiva aceitação social da constante e continua aplicação do aparato reformista em educação, justificado como necessário para a adequação formativa do indivíduo face às novas exigências do mundo do trabalho.

A categoria trabalho parece não se firmar como princípio formativo em seu alcance dialético e contraditório. $\mathrm{Na}$ experiência capitalista contemporânea, a expectativa aliena a condição de trabalho, bem como as experiências formativas e culturais. Assim, figura como treinamento a serviço da lógica mutante das experiências laborais no sistema produtivo capital.

As reformas educacionais em curso, tais como a reforma curricular articulada à consolidação de uma nova Base Nacional Comum Curricular, justificada como necessária para a adequação do sistema de ensino às novas exigências do mundo do trabalho, precisam ser compreendidas, em seus pressupostos políticopedagógicos, como política inerente às mudanças do trabalho sob a mediação do capital.

\section{AGRADECIMENTOS}

O presente trabalho é realizado com o apoio da Universidade Federal de Mato Grosso do Sul - UFMS/MEC - Brasil e no âmbito do GForP - Grupo de Estudo e Pesquisa em Formação de Professores da UFMS/CPTL.

\section{REFERÊNCIAS}

ANTUNES, R. O privilégio da servidão: o novo proletariado de serviços na era digital. São Paulo: Boi Tempo, 2018.

ANTUNES, R. Os sentidos do trabalho: Ensaios sobre a afirmação e negação do trabalho. 2. ed. São Paulo: Boi Tempo, 2009.

BENITE, Anna Maria Canavarro. Considerações sobre o Enfoque Epistemológico do Materialismo Histórico-Dialético na Pesquisa Educacional. 
Revista Iberoamericana de Educación, n. 50, p. 1-15, set. 2019. Disponivel em: https://rieoei.org/historico/deloslectores/3024Be nite.pdf. Acesso em: 07 jan. 2020.

BLOCH, M. A Sociedade Feudal. Tradução de Emanuel Lourenço Godinho. São Paulo: Edições 70, 2009. p. 83-94.

BRASIL. Secretaria de Educação Fundamental. Parâmetros curriculares nacionais: terceiro e quarto ciclos do ensino fundamental: introdução aos parâmetros curriculares nacionais. Brasília: MEC/SEF, 1998.

BRASIL. Secretaria de Educação Fundamental. Base Nacional Comum Curricular: Ensino Médio. Brasília: MEC/Secretaria de Educação Básica, 2018.

FRANCELINO, S. M. R. L. As transformações do mundo do trabalho e a atividade docente. In: Educação e psicologia: reflexões a partir da teoria sócio-histórica. Org. Inara Barbosa Leão. Campo Grande: Ed. UFMS, 2003. p. 121-144.

FRIGOTTO, G. Novos fetiches mercantis da pseudoteoria do capital humano no contexto do capitalismo tardio. In: FRIGOTTO, G. As políticas públicas para a educação no Brasil contemporâneo: limites e contradições. Juiz de Fora: Ed. UFJF, 2011. p. 18-36.

FRIGOTTO, G. O Enfoque da Dialética Materialista Histórica na Pesquisa Educacional. In.: FAZENDA, I. (Org). Metodologia da Pesquisa Educacional. São Paulo: Cortez, 1997. p. $69-90$.

GATTI JUNIOR, D. A Pedagogia Tecnicista no Contexto Brasileiro do Golpe de 1964: o projeto educacional do Instituto de Pesquisa e Estudos Sociais (1961-1972). Cadernos de História da Educação, Uberlândia, v. 9, n. 1, p. 45-63, jan./jun. 2010. Disponível em: http://www.seer.ufu.br/index.php/che/article/vi ew/7451. Acesso em: 07 jan. 2020.

JACOMELI, M. R. M. A lei 5.692 de 1971 e a presença dos preceitos liberais e escola novistas: os estudos sociais e a formação da cidadania. In: Revista HISTEDBR, Campinas, n. 39. p. 76-90, 2010. Disponível: /histedbr/article/view/8639718. Acesso em: 07 jan. 2020. DOI: 10.20396/rho.v10i39.8639718.

KOZUL, P. Tendencias historiográficas sobre el Feudalismo tardío y su abordaje en el Nivel Medio. Reproducción y dominación material. Anuario de la Escuela de Historia Virtual, Córdoba, v. 5, n. 5, p. 23-26, 2014. Disponível em: file://D:/Downloads/Dialnet-

TendenciasHistoriograficasSobreElFeudalismoTar dioY-5179694.pdf. Acesso em: 07 jan. 2020.

RIBEIRO, A. F. Taylorismo, Fordismo e Toyotismo. Lutas Sociais, São Paulo, v. 19 , n. 35 , p. 65-79, $2015 . \quad$ Disponível em: https://revistas.pucsp.br/Is/article/view/26678.

Acesso em: 07 jan. 2020.

RAMOS, M. N. A Pedagogia da Competências: autonomia ou adaptação? São Paulo: Cortez, 2001.

SILVA, A. V. M. A pedagogia tecnicista e a organização do sistema de ensino brasileiro. In: Revista HISTEDBR On-line, Campinas, n. 70. p. 197-209, 2016. Disponível em: https://periodicos.sbu.unicamp.br/ojs/index.php histedbr/article/view/8644737/0. Acesso em 07 jan. 2020: DOI: 10.20396/rho.v16i70.8644737.

TAYLOR, F. W. Princípios de administração científica. 6. ed. São Paulo: Atlas, 1966.

TOCQUEVILLE, A. $\mathbf{O}$ antigo regime e a revolução. Tradução de Yvonne Jean. 4. ed. Brasília: Editora Universidade de Brasília, 1997.

https://periodicos.sbu.unicamp.br/ojs/index.php 